\title{
Effects of leukemia inhibitory factor receptor on the adipogenic differentiation of human bone marrow mesenchymal stem cells
}

\author{
TAO WANG ${ }^{1}$, RUIQIAO YAN ${ }^{2}$, XIAOYUAN XU ${ }^{1}$, HUAN YU $^{1}$, \\ JIANFANG WU ${ }^{1}$, YAOFANG YANG ${ }^{1}$ and WEIDONG LI ${ }^{1}$ \\ ${ }^{1}$ Key Laboratory of System Bio-Medicine of Jiangxi Province, Jiujiang University; ${ }^{2}$ Clinical Skills Center, \\ Affiliated Hospital of Jiujiang University, Jiujiang, Jiangxi 332000, P.R. China
}

Received June 25, 2018; Accepted April 1, 2019

DOI: $10.3892 / \mathrm{mmr} .2019 .10140$

\begin{abstract}
Leukemia inhibitory factor (LIF) modulates various biological processes. Although previous studies have described the effects of LIF on adipocyte differentiation, the role of LIF receptor (LIFR) on adipocyte differentiation remains unclear. Using reverse transcription-quantitative PCR (RT-qPCR), LIFR expression was demonstrated to increase during adipogenic differentiation of human bone marrow mesenchymal stem cells (hMSCs), indicating that LIFR may be involved in this process. To further evaluate the association between LIFR and adipogenic differentiation, lentivirus-mediated LIFR knockdown was performed in hMSCs. Cells were divided into two groups: Negative control group and LIFR-knockdown group. During the adipogenic differentiation process, intracellular lipid accumulation was assessed with Oil Red $\mathrm{O}$ staining at various time points (days 3,6 and 9). Additionally, the mRNA and protein expression levels of LIF, LIFR and three molecular indicators of adipogenesis, peroxisome proliferator-activated receptor $\gamma$ (PPAR $\gamma)$, CCAAT enhancer binding protein $\alpha(\mathrm{C} / \mathrm{EBP} \alpha)$ and fatty acid binding protein 4 (FABP4/aP2), were assessed by RT-qPCR and western blotting. The culture supernatant was collected to evaluate the concentration of LIF using ELISA. The present results suggested that LIFR expression progressively increased during adipogenic differentiation of hMSCs. Conversely, LIFR knockdown significantly suppressed this process. Additionally, PPAR $\gamma, \mathrm{C} / \mathrm{EBP} \alpha$ and aP2 were inhibited following LIFR knockdown. In contrast with LIFR, the expression levels of LIF were significantly decreased after the initiation of adipogenic differentiation. Therefore, the
\end{abstract}

Correspondence to: Professor Yaofang Yang or Professor Weidong Li, Key Laboratory of System Bio-Medicine of Jiangxi Province, Jiujiang University, 17 Lufeng Road, Jiujiang, Jiangxi 332000, P.R. China

E-mail:289467055@qq.com

E-mail: weidong.li@jju.edu.cn

Key words: leukemia inhibitory factor, leukemia inhibitory factor receptor, adipogenic differentiation, human bone marrow mesenchymal stem cells expression levels of LIF and LIFR exhibited opposite trends. Collectively, the present results suggested that LIFR promoted adipogenic differentiation, whereas LIF may negatively regulate this process.

\section{Introduction}

At present, obesity poses a major health problem worldwide. Obesity is associated with mortality and multiple comorbidities, including cancer and various cardiometabolic disorders $(1,2)$. Modulation of adipogenesis may be used in the treatment of obesity (3). Additionally, elucidating the molecular mechanisms underlying adipogenesis may have important applications, in particular for the development of novel treatments for obesity and other related metabolic disorders.

Mesenchymal stem cells from various types of tissues, including bone marrow, are able to differentiate into adipocytes, similar to the pluripotent stem cells found in fat tissue (4). Bone marrow human mesenchymal stem cells (hMSCs) exhibit self-renewal capabilities and are multipotent (5). A previous in vitro study suggested that hMSCs may differentiate, not only into adipocytes (6), but also into other cell types, including chondrocytes (7) and osteoblasts (8). Therefore, hMSC cultures may represent an optimal model for analyzing the molecular mechanisms that regulate adipogenesis in humans (9).

The leukemia inhibitory factor (LIF) receptor (LIFR) consists of $\alpha$ and $\beta$ subunits $(10,11)$. LIFR can be activated by LIF, which induces heterodimerization of the two subunits of the receptor, thus activating protein phosphorylation and downstream signaling pathways involved in various biological processes (12-14). LIF has been reported to exhibit various additional functions in adipocytes $(15,16)$. However, to the best of our knowledge, the number of studies investigating LIFR in the context of adipogenic differentiation remains limited. In the present study, the expression levels of LIFR were revealed to progressively increase during adipogenic differentiation of hMSCs, suggesting that LIFR may be involved in this process.

In order to investigate the regulatory role of LIFR in adipogenesis, lentivirus-mediated LIFR knockdown was performed in hMSCs, and the expression levels of LIF and LIFR were analyzed during adipogenic differentiation. Silencing LIFR 
expression significantly suppressed adipocyte differentiation. Furthermore, the expression levels of LIF and LIFR exhibited opposite trends. Collectively, the present results suggested that LIFR may promote adipogenic differentiation, whereas LIF may negatively regulate this process.

\section{Materials and methods}

Cell culture and adipocyte differentiation. Human bone marrow mesenchymal stem cells (hMSCs; HUXMA-01001) were purchased from Cyagen Biosciences, Inc. Cells were evaluated for specific surface protein expression using flow cytometry. Flow cytometry was performed using FACSCalibur (BD Biosciences). The following fluorescent-conjugated monoclonal antibodies were used in this study: Rat allophycocyanin (APC) anti-human/mouse CD44 (1:50; cat. no. 17-0441-82; clone IM7; eBioscience; Thermo Fisher Scientific, Inc.), APC mouse anti-human CD29 (1:50; cat. no. 303008; clone TS2/16, BioLegend, Inc.), FITC mouse anti-human CD105 (1:50; cat. no. 561443; Endoglin; clone 266; BD Biosciences), APC mouse anti-human CD45 (1:50; cat. no. 555485; clone H130; BD Biosciences) and APC mouse antihuman CD14 (1:50; cat. no. 17-0149-42; clone 61D3; eBioscience; Thermo Fisher Scientific, Inc.). The cells were washed with PBS with $3 \%$ fetal bovine serum (FBS; Gibco; Thermo Fisher Scientific, Inc.) after detachment with $0.05 \%$ trypsin-EDTA (Gibco; Thermo Fisher Scientific, Inc.). A total $5 \times 10^{5}$ cells were re-suspended in $50 \mu \mathrm{l}$ of PBS with $3 \%$ FBS, blocked with $10 \mu \mathrm{l}$ of FcR Blocking Reagent (cat. no. 130-059-901; Miltenyi Biotec $\mathrm{GmbH}$ ) for $10 \mathrm{~min}$ at room temperature, and incubated with each type of the antibodies as listed above, for $30 \mathrm{~min}$ at $4^{\circ} \mathrm{C}$ in the dark. After incubation, the cells were washed twice in PBS with $3 \%$ FBS, and re-suspended in $500 \mu 1$ of PBS with $3 \%$ FBS for flow cytometry. The fluorescence intensity of the cells was evaluated using a FACSAria instrument, and data were analyzed with the FlowJov10.0.7 software (FlowJo LLC). hMSCs were confirmed to be positive for CD44, CD29 and CD105 (>70\%) and negative for CD45 and CD14 $(<5 \%)$.

Cells were grown to a cell density of $5 \times 10^{4}$ cells $/ \mathrm{cm}^{2}$ in OriCell hMSCs growth medium (cat. no. HUXMA-9001c; Cyagen Biosciences, Inc.), supplemented with 10\% FBS, $100 \mathrm{IU} / \mathrm{ml}$ penicillin (Gibco; Thermo Fisher Scientific, Inc.), $100 \mu \mathrm{g} / \mathrm{ml}$ streptomycin (Gibco; Thermo Fisher Scientific, Inc.) and $0.4 \%$ glutamine (Gibco; Thermo Fisher Scientific, Inc.). Cells were maintained at $37^{\circ} \mathrm{C}$ in an atmosphere containing $5 \% \mathrm{CO}_{2}$ and $95 \%$ humidity. Cells were passaged using $0.25 \%$ trypsin-EDTA (Gibco; Thermo Fisher Scientific, Inc.) every 3-4 days. hMSCs were used at the fifth passage.

Confluent hMSCs were incubated for 2 additional days and adipogenesis was induced using Dulbecco's modified Eagle's medium containing $10 \% \mathrm{FBS}, 10 \mu \mathrm{g} / \mathrm{ml}$ insulin, $0.5 \mathrm{mM}$ 3-isobutyl-1-methylxanthine and $0.5 \mathrm{mM}$ dexamethasone. All reagents were obtained from Gibco (Thermo Fisher Scientific, Inc.). Adipogenic differentiation was induced for 9 days and the medium was replaced every 3 days.

Lentiviral infection and screening of hMSCs. A lentiviral vector used to induce LIFR knockdown was purchased from Shanghai GeneChem Co., Ltd. A short hairpin RNA
(shRNA) targeting human LIFR was designed (target sequence, 5'-TCCCATTGTTGCACCAAAT-3'). In addition, a negative control (NC) shRNA was used (sequence, 5'-TTC TCCGAACGTGTCACGT-3'). Chemically synthesized DNA oligonucleotides (Shanghai GeneChem Co., Ltd.) were cloned into the pGV248-green fluorescent protein (GFP) vector lentivirus (Shanghai GeneChem Co., Ltd.). hMSCs were infected with LIFR shRNA vector or with NC. The lentivirus titer was determined through serial dilutions. hMSCs were seeded into 6-well plates at a density of $5 \times 10^{4}$ cells $/ \mathrm{cm}^{2}$, and cultured to $20-30 \%$ confluence. Cells were infected with $1 \times 10^{8}$ transducing units/ml lentivirus (volume, $10 \mu \mathrm{l}$; multiplicity of infection, 5) in complete medium with $5 \mu \mathrm{g} / \mathrm{ml}$ polybrene (Shanghai GeneChem Co., Ltd.). Subsequently, the infected cells were incubated at $37^{\circ} \mathrm{C}$ for $10 \mathrm{~h}$, after which, the medium was replaced with fresh medium and cells were incubated at $37^{\circ} \mathrm{C}$ for an additional $72 \mathrm{~h}$. Infected cells were screened after culturing for $48 \mathrm{~h}$ in medium containing $0.5 \mu \mathrm{g} / \mathrm{ml}$ puromycin. The medium was replaced after 1-2 days, and screening continued for 6 days. Fluorescence microscopy was performed on living cells in order to evaluate the efficiency of lentiviral infection. Additionally, prior to adipogenic differentiation, LIFR expression was assessed using quantitative PCR (qPCR) to examine infection efficiency after infection $72 \mathrm{~h}$.

During adipogenic differentiation of hMSCs, the development of intracellular lipid droplets was assessed at various time points (3, 6 and 9 days) using Oil Red O. Subsequently, cells were harvested for analysis of the mRNA and protein expression levels of LIF, LIFR, peroxisome proliferator-activated receptor $\gamma$ (PPAR $\gamma)$, CCAAT enhancer binding protein $\alpha$ $(\mathrm{C} / \mathrm{EBP} \alpha)$ and $\mathrm{aP} 2$.

Oil Red $O$ staining and lipid measurement. After washing with PBS, fixation was performed with $4 \%$ formalin at room temperature for $30 \mathrm{~min}$. Samples were then washed twice with PBS and incubated for $30 \mathrm{~min}$ with $60 \%$ saturated Oil Red O (Sigma-Aldrich; Merck KGaA) at room temperature. After two further washes with PBS, the cells were visualized using light microscopy (IX73; Olympus Corporation). Subsequently, stained cells were treated with isopropanol and a microplate reader (Bio-Rad Laboratories, Inc.) was used to measure the optical density at $490 \mathrm{~nm}$, in order to quantify the intracellular levels of lipid droplets.

Reverse transcription (RT)-qPCR. RNA was extracted with TRIzol ${ }^{\circledR}$ reagent (Invitrogen; Thermo Fisher Scientific, Inc.), according to the manufacturer's protocol. First-strand cDNA was obtained using the Reverse Transcription System and Oligo (dT), according to the manufacturer's protocol (Thermo Fisher Scientific, Inc.). qPCR was performed using a SYBR Premix Ex Taq kit (Toyobo Life Science) with a 7300 real-time PCR system (Applied Biosystems; Thermo Fisher Scientific, Inc.). The PCR thermocycling conditions consisted of an initial denaturation at $95^{\circ} \mathrm{C}$ for $1 \mathrm{~min}$, followed by 40 cycles at $95^{\circ} \mathrm{C}$ for $15 \mathrm{sec}$ and at $60^{\circ} \mathrm{C}$ for $34 \mathrm{sec}$. Relative expression levels were quantified using the $2^{-\Delta \Delta \mathrm{Cq}}$ method (17). The expression levels of the target genes were normalized to the expression levels of $\beta$-actin. The sequences of the primers used are listed in Table I. 
Table I. Primer sequences used for reverse transcription-quantitative PCR analysis.

Gene symbol

Primer sequence $\left(5^{\prime}-3^{\prime}\right)$
Amplicon length (bp)
F: GGGATGTCTCATAATGCCATCAG
R: GCCCTCGCCTTTGCTTTG
F: CCAAGAAGTCGGTGGACAAGAAC
R: CACCTTCTGCTGCGTCTCCA
F: GGATGATAAACTGGTGGTGGAATG
R: CAGAATGTTGTAGAGTTCAATGCGA
F: AGCCTCAAGCAAAACCAGAA
R: TTGGCCTGAGGTCTGTAACC
F: CTGTTGGTTCTGCACTGGAA
R: CCCCTGGGCTGTGTAATAGA
R: TACCCCTCGTAGATGGGCACA

$\operatorname{PPAR} \gamma$

$\mathrm{aP2}$

LIFR

LIF

$\beta$-actin
97

122

144

154

160

aP2, fatty acid binding protein 4; C/EBP $\alpha$, CCAAT enhancer binding protein $\alpha$; LIF, leukemia inhibitory factor; LIFR, LIF receptor; PPAR $\gamma$, peroxisome proliferator-activated receptor $\gamma$; F, forward; R, reverse.

Western blotting. Cells were lysed using RIPA buffer [50 mM Tris (pH 7.4), 1\% Triton X-100, $150 \mathrm{mM} \mathrm{NaCl,} \mathrm{0.1 \%} \mathrm{SDS,}$ $1 \%$ sodium deoxycholate, $1 \mathrm{mmol} / \mathrm{l}$ sodium orthovanadate, $50 \mathrm{mmol} / 1$ sodium fluoride, $1 \mathrm{mM}$ EDTA and $2 \mu \mathrm{g} / \mathrm{ml}$ leupeptin]. The amount of protein was measured using a Micro bicinchoninic acid Protein assay kit following the protocol provided by the manufacturer (Thermo Fisher Scientific, Inc.). Cell samples were diluted 10,20 and 40 times in $\mathrm{NaCl} 0.9 \%$ and after $2 \mathrm{~h}$ incubation at $37^{\circ} \mathrm{C}$, absorbance was measured using the Bio-Rad iMark microplate reader (Bio-Rad Laboratories, Inc.). The extracted proteins were boiled for $5 \mathrm{~min}$ in 5x SDS sample buffer. Electrophoresis was performed on $15 \mu \mathrm{g}$ of protein loaded onto $10 \%$ SDS-PAGE, followed by transfer to PVDF membranes (EMD Millipore). Membranes were blocked for $90 \mathrm{~min}$ with $5 \%$ skim milk for $120 \mathrm{~min}$ at room temperature, followed by incubation at $4^{\circ} \mathrm{C}$ overnight with primary antibodies. The primary antibodies used were: Mouse anti-LIFR (1:1,000; cat. no. ab89792), rabbit anti-PPAR $\gamma$ (1:1,000; cat. no. ab191407), rabbit anti-C/EBP $\alpha$ (1:1,000; cat. no. ab40764), rabbit anti-aP2 (1:1,000; cat. no. ab92501) and mouse anti- $\beta$-actin (1:2,000; cat. no. ab173838; all Abcam). Subsequently, membranes were incubated for $60 \mathrm{~min}$ with the appropriate secondary antibody at room temperature: Anti-mouse horseradish peroxidase (HRP)-conjugated IgG (1:5,000; cat. no. 7076P2; Cell Signaling Technology, Inc.) or anti-rabbit HRP-conjugated IgG (1:5,000; cat. no. 7074P2; Cell Signaling Technology, Inc.). Finally, enhanced chemiluminescence (cat. no. P0018; BeyoECL Plus; Beyotime Institute of Biotechnology) was performed to evaluate the intensity of the protein bands.

Quantification of LIF concentration. LIF protein concentration was assessed in the cell culture supernatant using an ELISA kit (cat. no. SX01091; Shanghai Senxiong Biotech Industry Co., Ltd.), according to the manufacturer's protocol. Absorbance was measured at $450 \mathrm{~nm}$ following background correction. LIF concentration was calculated using a standard curve.
Statistical analysis. All experiments were performed in triplicate. Data are presented as the mean \pm standard deviation. SPSS (version 16.0; SPSS, Inc.) was used to perform statistical analyses. Statistical analysis was performed using one-way analysis of variance (ANOVA) and Tukey's post-hoc test. $\mathrm{P}<0.05$ was considered to indicate a statistically significant difference.

\section{Results}

LIFR expression during adipogenic differentiation. The expression levels of LIFR progressively increased during adipogenic differentiation (Fig. 1), suggesting that LIFR may be involved in the adipogenic differentiation of hMSCs.

Identification of stably infected hMSCs. hMSCs with stable infection were identified by treating cells with $0.5 \mu \mathrm{g} / \mathrm{ml}$ puromycin for 6 days. Inverted fluorescence microscopy was used to identify GFP-positive cells in both the NC group and in cells with knockdown of LIFR, indicating stable infection (Fig. 2A).

The efficiency of lentiviral infection was confirmed by RT-qPCR analysis. The expression levels of LIFR were reduced $\sim 3$-fold following LIFR knockdown compared with cells in the NC group (Fig. 2B).

Oil Red $O$ staining. Adipogenesis was investigated in hMSCs at various time points (3,6 and 9) following incubation in adipogenic medium. The majority of cells exhibited cytoplasmic lipid vesicles, as assessed by Oil Red O staining (Fig. 3A). LIFR knockdown inhibited adipogenic differentiation. Furthermore, the intracellular lipid content and the number of lipid droplets were lower in the LIFR-knockdown group compared with in the NC group (Fig. 3B).

mRNA expression levels of LIF, LIFR and adipogenic markers during adipogenic differentiation. The expression 


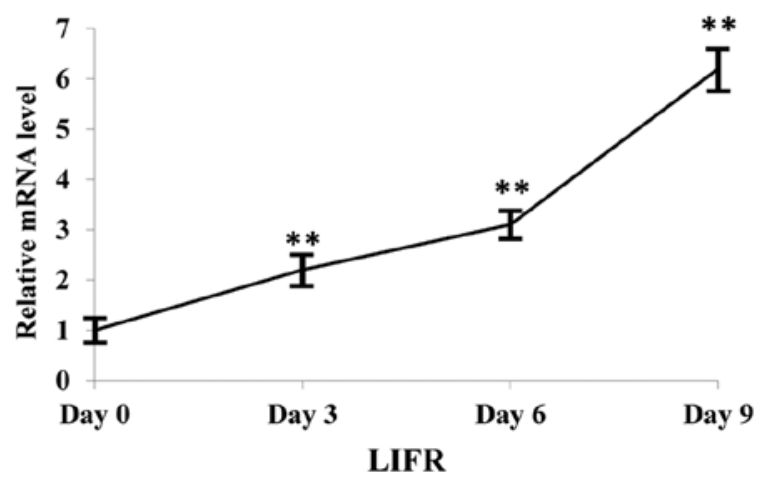

Figure 1. Expression levels of LIFR during adipogenesis at different time points, as assessed by reverse transcription-quantitative PCR analysis. ${ }^{* *} \mathrm{P}<0.01$ vs. day 0 . LIFR, leukemia inhibitory factor receptor.

A
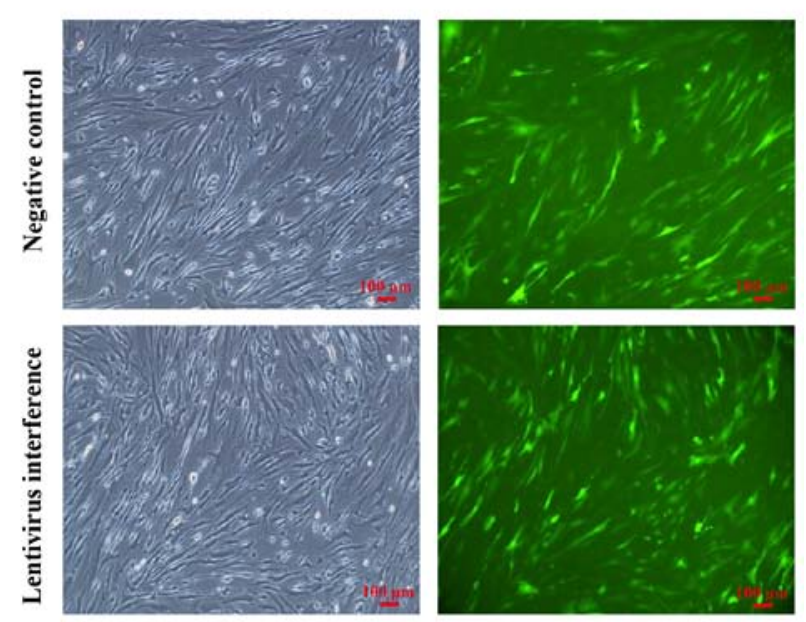

B

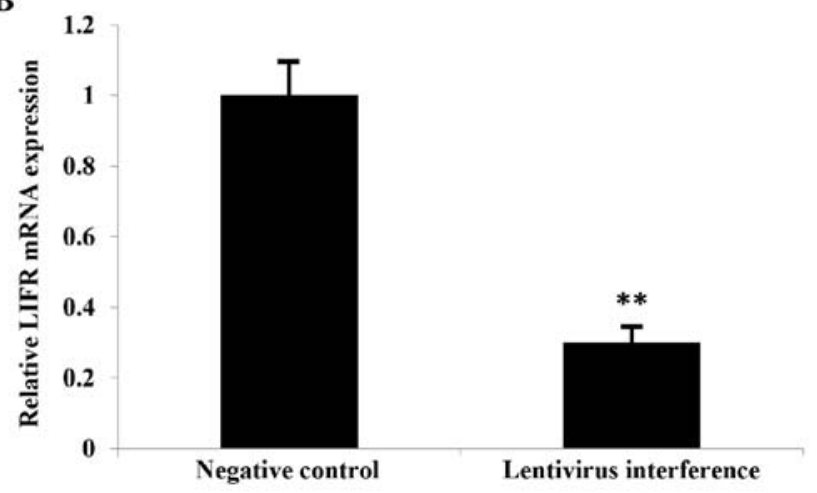

Figure 2. Identification of stably infected hMSCs. (A) Infected cells visualized under light and fluorescence microscopy. (B) Expression levels of LIFR were quantified by reverse transcription-quantitative PCR analysis. ${ }^{* *} \mathrm{P}<0.01$ vs. negative control. LIFR, leukemia inhibitory factor receptor.

levels of LIF, LIFR, PPAR $\gamma, \mathrm{C} / \mathrm{EBP} \alpha$ and aP2 were measured by RT-qPCR in LIFR-knockdown and NC groups (Fig. 4). LIFR downregulation significantly suppressed adipocyte differentiation, alongside inhibition of PPAR $\gamma, \mathrm{C} / \mathrm{EBP} \alpha$ and $\mathrm{aP} 2$ expression (Fig. 4A-C). Furthermore, the mRNA expression levels of LIF were significantly decreased following induction of adipogenic differentiation in the negative control and LIFR knockdown groups, respectively (Fig. 4E). Conversely,
A
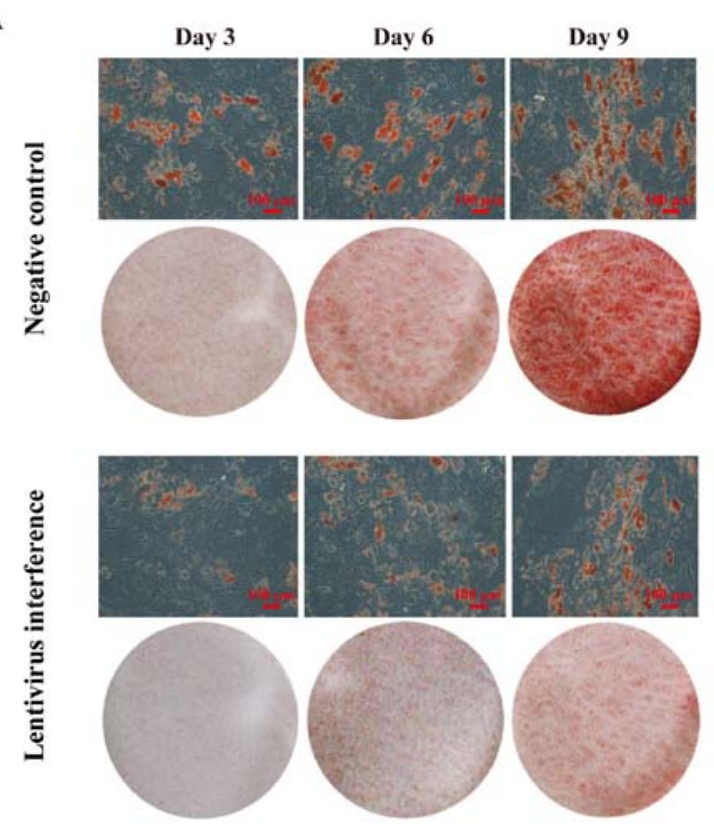

B

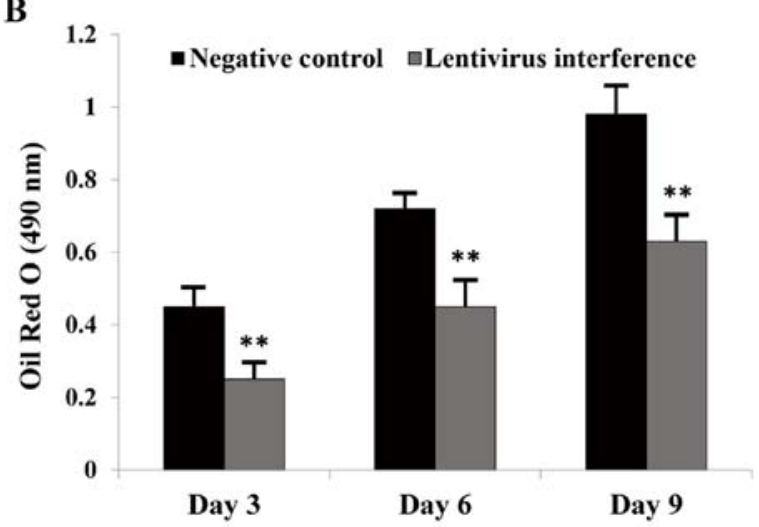

Figure 3. Leukemia inhibitory factor receptor knockdown significantly impairs adipogenic differentiation. (A) Oil Red O-stained adipocytes at various time points during adipogenic differentiation. (B) Cytoplasmic lipid droplets in adipocytes at various time points during adipogenic differentiation. ${ }^{* *} \mathrm{P}<0.01$ vs. negative control.

the mRNA expression levels of LIFR exhibited an opposite trend (Fig. 4D).

Protein expression levels of LIF,LIFR andmarkers during adipogenesis. LIFR, PPAR $\gamma, \mathrm{C} / \mathrm{EBP} \alpha$ and aP2 mRNA expression was elevated in each group, as aforementioned. Consistently, western blotting revealed that the protein expression levels of PPAR $\gamma$, $\mathrm{C} / \mathrm{EBP} \alpha$ and $\mathrm{aP} 2$ appeared to be decreased during adipogenesis following LIFR knockdown (Fig. 5A). Additionally, ELISA was performed to measure the concentration of LIF in the medium, and LIF was decreased during adipogenesis in the negative control and LIFR knockdown groups (Fig. 5B).

\section{Discussion}

Adipogenic differentiation serves an important role in the development of obesity. The adipogenic differentiation of hMSCs through preadipocytes may represent an important source of adipose tissue during obesity $(3,4,18)$. In the present 
A

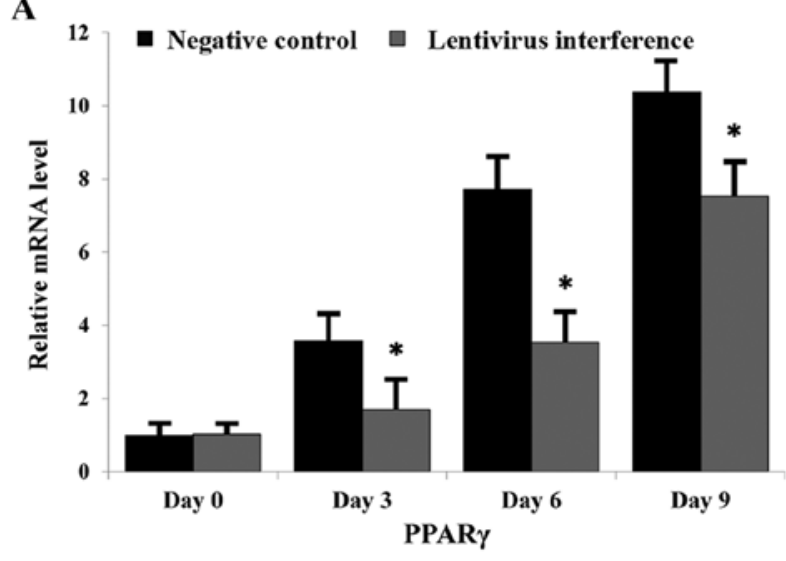

C

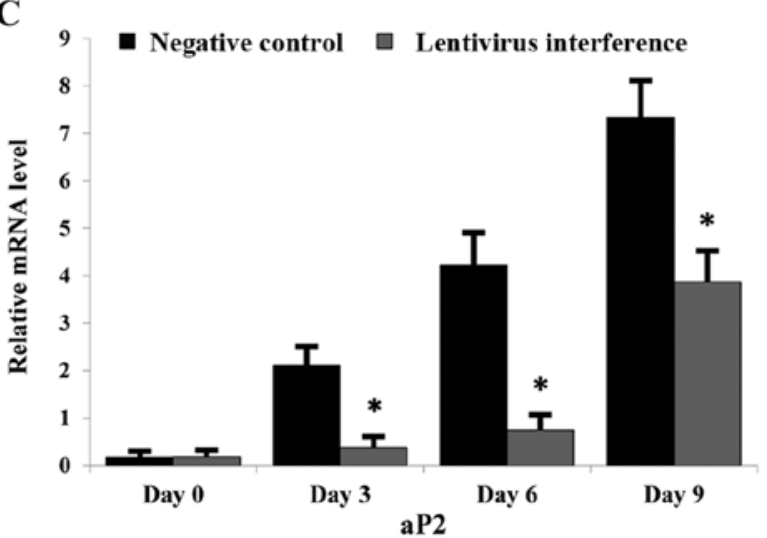

$\mathbf{E}$

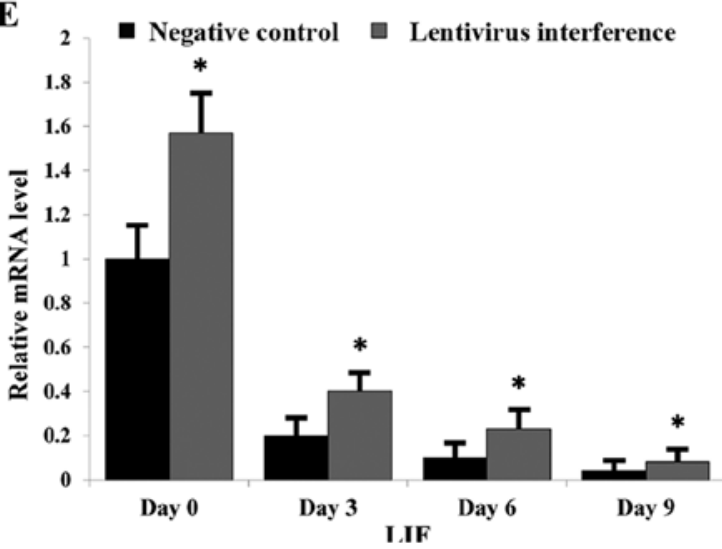

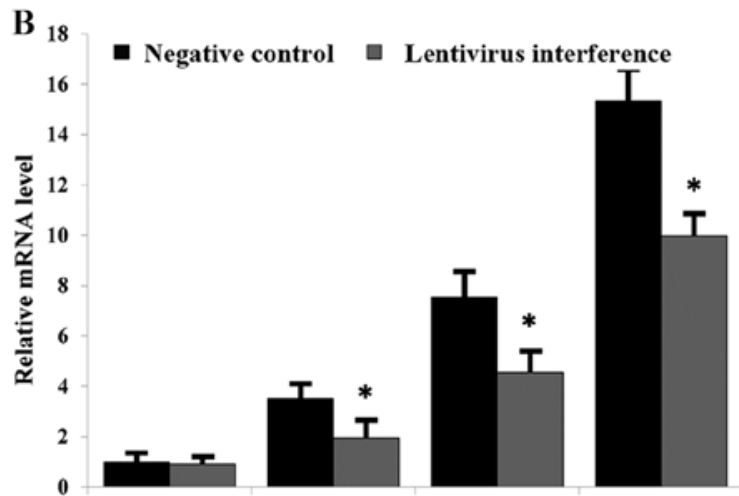

Day 0

Day 3

Day 6

Day 9

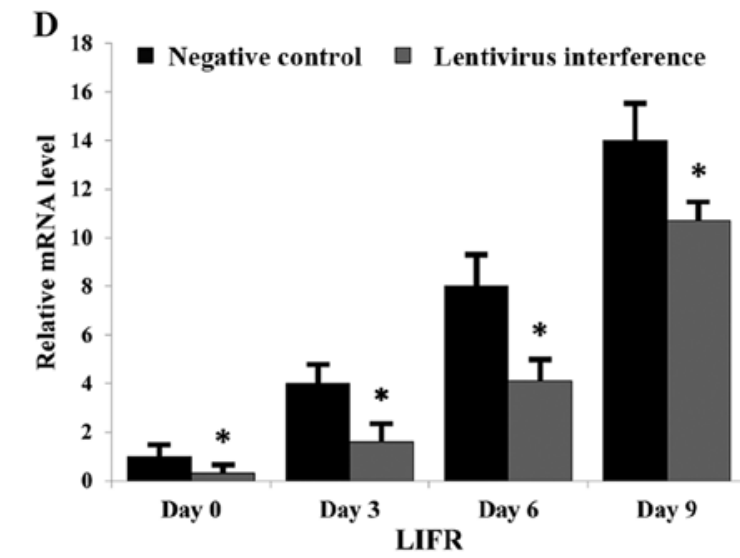

Day 0

Day 3

Day 9

Figure 4. mRNA expression levels of LIF, LIFR and adipogenic markers during adipogenic differentiation. Expression levels of (A) PPAR $\gamma$, (B) C/EBP $\alpha$, (C) aP2, (D) LIFR and (E) LIF in each group of cells, as assessed by reverse transcription-quantitative PCR. ${ }^{*} \mathrm{P}<0.05$ vs. negative control. aP2, fatty acid binding protein 4; C/EBP $\alpha$, CCAAT enhancer binding protein $\alpha$; LIF, leukemia inhibitory factor; LIFR, LIF receptor; PPAR $\gamma$, peroxisome proliferator-activated receptor $\gamma$.

study, LIFR expression was increased during the adipogenic differentiation of hMSCs, suggesting that this protein may be involved in the regulation of adipogenesis. To investigate this hypothesis, stable lentivirus-mediated infection was performed to efficiently downregulate the expression of LIFR in hMSCs. Subsequently, adipogenic differentiation of hMSCs was examined at different time points. LIFR downregulation significantly inhibited adipogenesis and the accumulation of intracellular lipids. The present findings indicated that LIFR may promote adipogenesis in these cells.

A previous study confirmed that microRNA (miR)-377-3p targeted LIFR and regulates adipogenic differentiation (19); however, the function of LIFR in adipogenesis had not been investigated. Therefore, the present study aimed to investigate the role of LIFR in adipogenic differentiation at various time points. In addition, the mRNA and protein expression levels of various molecular markers of adipogenesis, including PPAR $\gamma$, $\mathrm{C} / \mathrm{EBP} \alpha$ and $\mathrm{aP2}$, were examined. LIFR downregulation in hMSCs caused a significant reduction in the mRNA and protein expression levels of these markers during differentiation. PPAR $\gamma$ and C/EBP $\alpha$ are transcription factors that promote adipogenesis, which may act synergistically $(20,21)$. In addition, aP2 modulates lipid storage and metabolism, acting downstream of PPAR $\gamma$ and C/EBP $\alpha$ signaling $(22,23)$. The 


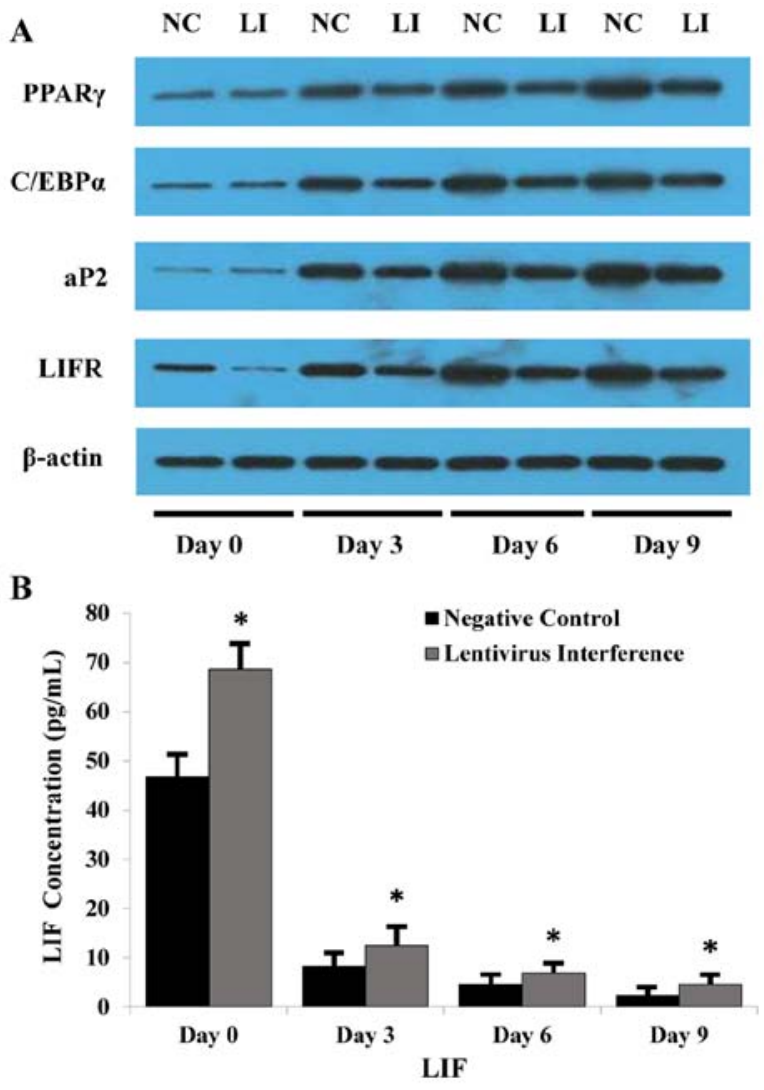

Figure 5. Protein expression levels of LIF, LIFR and adipogenic markers during adipogenic differentiation. (A) Protein expression levels of adipogenic markers and LIFR were decreased following LIFR knockdown (B) Quantification of LIF concentration in the cell culture supernatant, as assessed by ELISA. " $\mathrm{P}<0.05$ vs. negative control. aP2, fatty acid binding protein $4 ; \mathrm{C} / \mathrm{EBP} \alpha, \mathrm{CCAAT}$ enhancer binding protein $\alpha$; LI, lentivirus-mediated interference; LIF, leukemia inhibitory factor; LIFR, LIF receptor; NC, negative control; PPAR $\gamma$, peroxisome proliferator-activated receptor $\gamma$.

present results suggested that LIFR downregulation may be associated with a decrease in the expression levels of these three molecules, thus impairing adipogenic differentiation. Previous studies have demonstrated that these adipogenic markers are important transcription factors involved in adipogenic regulation, and in the pathophysiology of obesity and several endocrine-metabolic disorders (24-26). The present results indicated that LIFR may also be associated with these diseases.

In investigating LIFR function, it is important to examine LIF. LIF is a glycoprotein secreted by hMSCs (27) that is able to interact with LIFR, activating its downstream signaling pathway. Although previous studies have investigated the impact of LIF on adipogenic differentiation, the previous results were inconsistent or contradictory. For example, a previous study reported that LIF inhibits differentiation of 3T3-L1 adipocytes in vitro (28); however, in Ob1771 cells, LIF was revealed to promote differentiation (16). To the best of our knowledge, pre-adipocyte cell lines, including 3T3-L1 and Ob1771, are immortalized and may not fully mimic human primary cells due to their murine origin. Since primary hMSCs extracted from the bone marrow may more closely mirror the physiological context of adipogenic differentiation in humans, these cells were selected and investigated in the present study.
A number of previous studies have investigated the role of either LIF or LIFR $(15,16,27,28)$. Similarly, our previous study investigated the function of LIFR as a miR-377 target gene involved in adipogenic differentiation (19). To the best of our knowledge, the present study is the first to investigate the relationship between the expression levels of LIF and LIFR during adipogenic differentiation. Previous studies have reported that the expression patterns of LIF and LIFR are similar in certain tissues and cells $(29,30)$. In the present study, the expression levels of LIF and LIFR exhibited opposite trends during adipogenic differentiation of hMSCs. After initiation of adipogenesis, the expression levels of LIF were decreased, whereas the expression levels of LIFR were increased. LIFR knockdown was also associated with an increased expression of LIF compared with in the NC group, thus suggesting that LIF may be a negative regulator of adipogenic differentiation. LIF is an inhibitor of cell differentiation in mouse embryonic stem cells $(31,32)$. Although LIF overexpression and/or knockout were not performed in the present study, results from previous studies support our hypothesis of the role of LIF in cell differentiation. The present results suggested that LIFR and LIF may serve opposite roles during adipogenic differentiation of hMSCs. Previous studies investigated the use of hMSCs for the treatment of aplastic anemia $(33,34)$. Notably, the relationship between the expression levels of LIF and LIFR, and hematopoietic and bone marrow differentiation is an interesting aspect to address in future studies.

In addition to LIF, LIFR may interact with other ligands, including oncostatin $\mathrm{M}$ and ciliary neurotrophic factor, which may promote the activation of multiple downstream signaling pathways involved in adipogenic differentiation $(12,35,36)$, including the mitogen-activated protein kinase and Janus kinase/signal transducer and activator of transcription signaling pathways (12-14,37). Collectively, LIFR may be associated with various ligands and signaling pathways involved in adipogenic differentiation.

In conclusion, the present study suggested that LIFR may be a novel positive regulator of adipogenic differentiation. Conversely, LIF may negatively regulate adipogenic differentiation. The present findings suggested that LIFR-targeting treatments may represent novel potential strategies to treat obesity and other associated disorders.

\section{Acknowledgements}

Not applicable.

\section{Funding}

The present study was supported by The National Natural Science Foundation of China (grant no. 81460221), the Jiangxi Province Natural Science Foundation of China (grant nos. 20161BAB205197 and 20132BAB205012) and the Development Plan of Young and Middle-aged Teachers in General Universities of Jiangxi Province (grant no. 2012-132).

\section{Availability of data and materials}

All data generated or analyzed during this study are included in this published article. 


\section{Authors' contributions}

TW, YY and WL designed the present study. RY, XX and HY performed the experiments. JW analyzed the data. TW wrote the paper.

\section{Ethics approval and consent to participate}

Not applicable.

\section{Patient consent for publication}

Not applicable.

\section{Competing interests}

The authors declare that they have no competing interests.

\section{References}

1. Kopelman PG: Obesity as a medical problem. Nature 404: 635-643, 2000.

2. Kahn BB and Flier JS: Obesity and insulin resistance. J Clin Invest 106: 473-481, 2000.

3. Keller M, Hopp L, Liu X, Wohland T, Rohde K, Cancello R, Klös M, Bacos K, Kern M, Eichelmann F, et al: Genome-wide DNA promoter methylation and transcriptome analysis in human adipose tissue unravels novel candidate genes for obesity. Mol Metab 6: 86-100, 2016.

4. Otto TC and Lane MD: Adipose development: From stem cell to adipocyte. Crit Rev Biochem Mol Biol 40: 229-242, 2005.

5. Pittenger MF, Mackay AM, Beck SC, Jaiswal RK, Douglas R, Mosca JD, Moorman MA, Simonetti DW, Craig S and Marshak DR: Multilineage potential of adult human mesenchymal stem cells. Science 284: 143-147, 1999.

6. Helder MN, Knippenberg M, Klein-Nulend J and Wuisman PI: Stem cells from adipose tissue allow challenging new concepts for regenerative medicine. Tissue Eng 13: 1799-1808, 2007.

7. Barry F, Boynton RE, Liu B and Murphy JM: Chondrogenic differentiation of mesenchymal stem cells from bone marrow: Differentiation-dependent gene expression of matrix components. Exp Cell Res 268: 189-200, 2001.

8. Arinzeh TL: Mesenchymal stem cells for bone repair: Preclinical studies and potential orthopedic applications. Foot Ankle Clin 10: 651-665, 2005.

9. Subash-Babu P and Alshatwi AA: Aloe-emodin inhibits adipocyte differentiation and maturation during in vitro human mesenchymal stem cell adipogenesis. J Biochem Mol Toxicol 26: 291-300, 2012.

10. del Valle I, Rudloff S, Carles A, Li Y, Liszewska E, Vogt R and Kemler R: E-cadherin is required for the proper activation of the Lifr/Gp130 signaling pathway in mouse embryonic stem cells. Development 140: 1684-1692, 2013.

11. Pan W, Cain C, Yu Y and Kastin AJ: Receptor-mediated transport of LIF across blood-spinal cord barrier is upregulated after spinal cord injury. J Neuroimmunol 174: 119-125, 2006.

12. Plun-Favreau H, Perret D, Diveu C, Froger J, Chevalier S, Lelièvre $\mathrm{E}$, Gascan $\mathrm{H}$ and Chabbert $\mathrm{M}$ : Leukemia inhibitory factor (LIF), cardiotrophin-1, and oncostatin M share structural binding determinants in the immunoglobulin-like domain of LIF receptor. J Biol Chem 278: 27169-27179, 2003.

13. White UA and Stephens JM: Neuropoietin activates STAT3 Independent of LIFR activation in adipocytes. Biochem Biophys Res Commun 395: 48-50, 2010.

14. Morton SD, Cadamuro M, Brivio S, Vismara M, Stecca T, Massani M, Bassi N, Furlanetto A, Joplin RE, Floreani A, et al: Leukemia inhibitory factor protects cholangiocarcinoma cells from drug-induced apoptosis via a PI3K/AKT-dependent Mcl-1 activation. Oncotarget 6: 26052-26064, 2015.

15. Ikeda S, Itoh S, Yamamoto Y, Matsushita K, Naruse H and Hayashi M: Developmental stage-dependent effects of leukemia inhibitory factor on adipocyte differentiation of murine bone marrow stromal cells. Cell Biochem Biophys 74: 11-17, 2016.
16. Aubert J,Dessolin S, Belmonte N, Li M, McKenzie FR, Staccini L, Villageois P, Barhanin B, Vernallis A, Smith AG, et al: Leukemia inhibitory factor and its receptor promote adipocyte differentiation via the mitogen-activated protein kinase cascade. J Biol Chem 274: 24965-24972, 1999.

17. Livak KJ and Schmittgen TD: Analysis of relative gene expression data using real-time quantitative PCR and the 2(-Delta Delta C(T)) method. Methods 25: 402-408, 2001.

18. Fernyhough ME, Hausman GJ, Guan LL, Okine E, Moore SS and Dodson MV: Mature adipocytes may be a source of stem cells for tissue engineering. Biochem Biophys Res Commun 368: 455-457, 2008

19. Li X, Yang Y, Yan R, Xu X, Gao L, Mei J, Liu J, Wang X, Zhang J, Wu P, et al: miR-377-3p regulates adipogenic differentiation of human bone marrow mesenchymal stem cells by regulating LIFR. Mol Cell Biochem 449: 295-303, 2018.

20. Farmer SR: Transcriptional control of adipocyte formation. Cell Metab 4: 263-273, 2006.

21. Kudo M, Sugawara A, Uruno A, Takeuchi K and Ito S: Transcription suppression of peroxisome proliferator-activated receptor gamma2 gene expression by tumor necrosis factor alpha via an inhibition of CCAAT/enhancer-binding protein delta during the early stage ofadipocyte differentiation. Endocrinology 145: 4948-4956, 2004.

22. Rosen ED, Walkey CJ, Puigserver P and Spiegelman BM: Transcriptional regulation of adipogenesis. Genes Dev 14: 1293-1307, 2000.

23. Zhang J, Huang Y, Shao H, Bi Q, Chen J and Ye Z: Grape seed procyanidin B2 inhibits adipogenesis of 3T3-L1 cells by targeting peroxisome proliferator-activated receptor $\gamma$ with miR-483-5p involved mechanism. Biomed Pharmacother 86: 292-296, 2017.

24. Floyd ZE and Stephens JM: Controlling a master switch of adipocyte development and insulin sensitivity: Covalent modifications of PPAR $\gamma$. Biochim Biophys Acta 1822: 1090-1095, 2012.

25. Furuhashi M, Tuncman G, Gorgun CZ, Makowski L, Atsumi G, Vaillancourt E, Kono K, Babaev VR, Fazio S, Linton MF, et al: Treatment of diabetes and atherosclerosis by inhibiting fatty-acid-binding protein FABP4. Nature 447: 959-965, 2007.

26. Hwang CS, Mandrup S, MacDougald OA, Geiman DE and Lane MD: Transcriptional activation of the mouse obese (ob) gene by CCAAT/enhancer binding protein alpha. Proc Natl Acad Sci USA 93: 873-877, 1996.

27. Oskowitz AZ, Lu J, Penfornis P, Ylostalo J, McBride J, Flemington EK, Prockop DJ and Pochampally R: Human multipotent stromal cells from bone marrow and microRNA: Regulation of differentiationand leukemia inhibitory factor expression. Proc Natl Acad Sci USA 105: 18372-18377, 2008.

28. Hogan JC and Stephens JM: Effects of leukemia inhibitory factor on 3T3-L1 adipocytes. J Endocrinol 185: 485-496, 2005.

29. Margioula-Siarkou C, Prapas Y, Petousis S, Milias S, Ravanos K, Kalogiannidis I, Mavromatidis G, Haitoglou C, Prapas N and Rousso D: LIF and LIF-R expression in the endometrium of fertile and infertile women: A prospective observational case-control study. Mol Med Rep 13: 4721-4728, 2016.

30. Li Y, Sun L, Zhao D, Ouyang J and Xiang M: Aberrant expression of leukemia inhibitory factor receptor (LIFR) and leukemia inhibitory factor (LIF) is associated with tubal pregnancy occurrence. Turk J Med Sci 45: 214-220, 2015.

31. Saito M, Asai Y,Imai K, Hiratoko $S$ and Tanaka K: Connexin 30.3 is expressed in mouse embryonic stem cells and is responsive to leukemia inhibitory factor. Sci Rep 7: 42403, 2017.

32. Cherepkova MY, Sineva GS and Pospelov VA: Leukemia inhibitory factor (LIF) withdrawal activates mTOR signaling pathway in mouse embryonic stem cells through the MEK/ERK/TSC2 pathway. Cell Death Dis 7: e2050, 2016.

33. Cheng HC, Liu SW, Li W, Zhao XF, Zhao X, Cheng M, Qiu L and Ma J: Arsenic trioxide regulates adipogenic and osteogenic differentiation in bone marrow MSCs of aplastic anemia patients through BMP4 gene. Acta Biochim Biophys Sin (Shanghai) 47: 673-679, 2015.

34. Lecourt S, Vanneaux V, Leblanc T, Leroux G, Ternaux B, Benbunan M, Chomienne C, Baruchel A, Marolleau JP, Gluckman E, et al: Bone marrow microenvironment in fanconi anemia: A prospective functional study in a cohort of fanconi anemia patients. Stem Cells Dev 19: 203-208, 2010. 
35. Natesh K, Bhosale D, Desai A, Chandrika G, Pujari R, Jagtap J, Chugh A, Ranade D and Shastry P: Oncostatin-M differentially regulates mesenchymal and proneural signature genes in gliomas via STAT3 signaling. Neoplasia 17: 225-237, 2015.

36. Wagener EM, Aurich M, Aparicio-Siegmund S, Floss DM, Garbers C, Breusing K, Rabe B, Schwanbeck R, Grötzinger J, Rose-John S and Scheller J: The amino acid exchange R28E in ciliaryneurotrophic factor (CNTF) abrogates interleukin-6 receptor-dependent but retains $\mathrm{CNTF}$ receptor-dependent signaling via glycoprotein 130 (gp130)/leukemia inhibitory factor receptor (LIFR). J Biol Chem 289: 18442-184450, 2014.
37. Liu GX, Zhu JC, Chen XY, Zhu AZ, Liu CC, Lai Q and Chen ST: Inhibition of adipogenic differentiation of bone marrow mesenchymal stem cells by erythropoietin via activating ERK and P38 MAPK. Genet Mol Res 14: 6968-6977, 2015 .

This work is licensed under a Creative Commons Attribution-NonCommercial-NoDerivatives 4.0 International (CC BY-NC-ND 4.0) License. 